\title{
Opioid-free anesthesia-dexmedetomidine as adjuvant in erector spinae plane block: a case series
}

\author{
Antonio Coviello* (1), Danilo Esposito, Roberta Galletta, Alfredo Maresca and Giuseppe Servillo
}

\begin{abstract}
Background: Laparoscopic pain is related to the stretching of the peritoneum and peritoneal irritation caused by insufflation of the parietal peritoneum with carbon dioxide. In 2017, erector spinae plane block (ESPB) was described for management of postoperative pain following open and laparoscopic abdominal surgery. The use of multimodal anesthesia reduces both intraoperative and postoperative opioid use and improves analgesia. The addition of dexmedetomidine to the anesthetic mixture significantly prolongs analgesia, without clinically significant side effects.
\end{abstract}

Case Presentation: We describe a series of three Caucasian women cases that illustrate the efficacy of bilateral ESPB performed at the level of the T7 transverse process to provide intraoperative and postoperative analgesia for laparoscopic gynecological surgery.

Conclusion: Further investigation is recommended to establish the potential for ESPB with dexmedetomidine as adjuvant as an opioid-free anesthetic modality in laparoscopic gynecological surgery.

Keywords: Case report, Dexmedetomidine, Multimodal analgesia, Opioid-free anesthesia, US-ESPB

\section{Background}

Erector spinae plane block (ESPB) is an interfascial block recently performed for thoracic analgesia [1]. The technique can be performed by injecting local anesthetic (LA) in the deep interfascial plane of the erector spinae muscle. This allows wide spread of LA between the erector spinae muscle and the costotransverse process in the paravertebral space, in the intervertebral foramina, in the epidural space and near the ipsilateral sympathetic chain [1]. In 2017, ESPB was described in several case reports for different clinical scenarios, including the management of postoperative pain following open and laparoscopic abdominal surgery and for thoracic and breast surgery [2]. Laparoscopic pain is related to the stretching of the peritoneum and peritoneal irritation caused by the

*Correspondence: antonio_coviello@live.it

Department of Anesthesiology and Intensive Care Medicine, Policlinico -

Federico II University Hospital, 80100 Naples, Italy activation of carbon anhydrase in response to insufflation of the parietal peritoneum with carbon dioxide [3]. The use of multimodal anesthesia reduces both intraoperative and postoperative opioids and improves analgesia [2]. The addition of dexmedetomidine to the LA significantly prolongs analgesia, without clinically significant side effects [4]. The use of an epidural catheter is considered a quality standard in abdominal surgery [5], but its placement is not always possible due to technical difficulties or patient-related conditions that contraindicate its insertion. ESPB therefore has the potential to provide both somatic and visceral sensory blocks, which would make it an ideal regional anesthetic technique for laparoscopic abdominal surgery [6]. It is possible to obtain multi-metameric analgesia compared to paravertebral block with a single puncture [7]. Opioid-free analgesia is beneficial in patients with respiratory insufficiency, obstructive sleep apnea syndrome (OSAS), chronic obstructive pulmonary 
disease (COPD) and in chronic treatment with opioids [8].

\section{Case presentation}

Caucasian women patients consented to the use of their personal data in the publication of this case series for scientific and clinical purposes. They were on chronic opioid treatment for severe pelvic pain. Patients had been taking oxycodone orally for at least 3 months (dose from 15 to $60 \mathrm{mg}$ as prescribed).

Surgery was performed under opioid-free general anesthesia. Premedication included midazolam $0.03 \mathrm{mg} / \mathrm{kg}$ and dexamethasone $4 \mathrm{mg}$ intravenously; bilateral ESPB at the T7 level was performed to provide intraoperative analgesia. Propofol ( $2 \mathrm{mg} / \mathrm{kg}$ intravenously) was given for the induction, rocuronium $(0.6 \mathrm{mg} / \mathrm{kg}$ intravenously) for muscle relaxation, remifentanil $(0.1 \mathrm{mcg} / \mathrm{kg} /$ minutes $)$ for tracheal intubation, and sevoflurane with minimum alveolar concentration (MAC) 1 for maintenance. The administration of remifentanil was stopped 5 minutes after tracheal intubation. Myo-resolution was monitored by train of four (TOF), and further boluses of $0.2 \mathrm{mg} /$ $\mathrm{kg}$ of rocuronium were administered to maintain a TOF $=0$. In the awakening phase, sugammadex $4 \mathrm{mg} / \mathrm{kg}$ was administered intravenously to revert the neuromuscular block and prevent postoperative residual curarization. For the ESPB, we proceeded with the technique as described by Forero et al. [1]. With the patient in sitting position, a high-frequency linear probe (Sonosite HLF $38 \times 13,6 \mathrm{MHz}$, Fujifilm Sonosite Europe, Amsterdam, Netherlands) was placed in longitudinal orientation at the level of the T7 transverse process (identified under ultrasound [US] guidance starting from the sacrum and going in the cranial direction), $3 \mathrm{~cm}$ from the midline. A $21 \mathrm{G} \times 85 \mathrm{~mm}$ block needle (Vygon Locoplex) was inserted in plane, with a cranio-caudal direction, until the tip was placed into the plane deep in the erector spinae muscle. After hydro-localization with $3 \mathrm{~mL}$ of saline solution to open the plane, $20 \mathrm{~mL}$ of $0.5 \%$ ropivacaine and dexmedetomidine $0.75 \mathrm{mcg} / \mathrm{kg}$ were injected. The procedure was practiced for both sides. Paracetamol $1 \mathrm{~g}$ was administered to all patients at 6, 12, 18 and 24 hours after surgery. In the case of acute pain, patients received an analgesic rescue dose according to the visual analog scale (VAS): if VAS $\leq 5$, ketorolac $30 \mathrm{mg}$ in $100 \mathrm{~mL}$ of saline solution was administered intravenously; if VAS $>5$, tramadol $100 \mathrm{mg}$ was administered intravenously. Episodes of postoperative nausea and vomiting (PONV) and postoperative shivering, pruritus, sedation, hemodynamic parameters (heart rate, noninvasive blood pressure, oxygen saturation) and recanalization times were recorded.

\section{First case}

A 28-year-old Caucasian women patient, weight $70 \mathrm{~kg}$, height $170 \mathrm{~cm}$, underwent operative laparoscopy because of left salpingectomy, bilateral ovarian cyst removal, cystic follicle and right corpus luteum excision. She also had several adhesions due to previous surgery that caused pelvic pain. In anamnesis she had endometriosis and nickel allergy. During the operation, no other opioid dose was used. The surgery time was 105 minutes. No surgical complications occurred. The patient did well from an analgesic standpoint, with a VAS score of 0 for the first 24 hours after surgery.

\section{Second case}

A 27-year-old Caucasian women patient, weight $60 \mathrm{~kg}$, height $165 \mathrm{~cm}$, underwent operative laparoscopy because of multiple voluminous uterine myomas. In anamnesis she had hyperprolactinemia and heterozygous mutation of PAI-1. The patient was under cabergoline therapy. During the operation, no other opioid dose was used. The surgery time was 120 minutes. No surgical complications occurred. Fifteen hours after surgery, the patient reported moderate pain (VAS $=3$ ) that was treated with paracetamol 1000 milligrams endovenous; no other analgesics were administered in 24 hours.

\section{Third case}

A 40-year-old Caucasian women patient, weight $60 \mathrm{~kg}$, height $165 \mathrm{~cm}$, underwent operative laparoscopy because of endometriosis. The pain from endometriosis was such that a complete gynecological examination could not be carried out, which required narcosis. In anamnesis she had hypertension pharmacologically controlled and dyslipidemia. During the operation, no other opioid dose was used. The surgery time was 120 minutes; the Trendelenburg position time was 90 minutes. The intra-abdominal pressure was kept higher $(15 \mathrm{mmHg})$ throughout the operation because of no optimal vision of surgical field due to a probable involvement of the left ureter. Nineteen hours after the surgery, the patient reported moderate pelvic pain (VAS $=4$ ) treated with ketorolac $30 \mathrm{mg}$ intravenously in $100 \mathrm{~mL}$ of saline solution; no other analgesics were administered in 24 hours.

\section{Discussion}

In a multimodal analgesia strategy, interfascial plane blocks can be a valid alternative and support for opioidfree analgesia. As Beloeil showed in his recent manuscript, patients suffering from chronic pain and/or consuming opioids before surgery benefit from opioidfree anesthesia. These patients are at higher risk of more intense severe postoperative acute pain when consuming 
more postoperative opioids. It has been shown that all this increases the risk of postsurgical pain chronicization [8].

No patient needed opioids to control intra- or postoperative pain. All patients who are managed daily in the operating room would benefit from this therapeutic strategy. According to Chin et al., since the erector muscle of the spine expands from the thoracic to the lumbar region, ESPB provides abdominal analgesia [3]. Studies on cadavers, and by magnetic resonance images, showed that a volume of $20 \mathrm{~mL}$ of fluid performed at the $\mathrm{T} 7$ transverse process spreads to C7-T2 cranially and L2-L3 caudally $[9,10]$. In our opinion, the direction of the needle is fundamental to address the spread of the anesthetic mixture. The best injection point for the mixture is the costotransverse process.

The limit, however, is currently the unpredictability of the diffusion of the mixture despite a correct execution of the technique. Our recent clinical case showed the efficacy and safety of a multidermatomal spread with the use of LA at anesthetic concentrations [11,12]. Since one of the most common causes of block failure is the injection of the LA into an improper site, that is the rib, in our clinical case the choice of a cranial-caudal approach was well considered before performing the procedure. The position of the patient is quite important for the execution of the block. According to our experience, the sitting position is the best in terms of simplification of the technique. To locate T7, we counted the laminae starting from the sacrum using the US method illustrated by Selvi's study [13]. Patients reported only low-intensity diffuse abdominal discomfort, probably due to peritoneal irritation related to gas insufflation during the laparoscopy [14], with multi-metameric involvement. In our experience, the intensity of postoperative pain was directly related to the surgical time and the intra-abdominal pressure level of pneumoperitoneum; instead, pain localization is directly related to the kind of pathology and spread of the anesthetic mixture at the caudal lumbar root level, and unpredictable variable. Although epidural analgesia represents the gold standard in abdominal surgery with severe pain, the ESPB safety profile is different from that of epidural analgesia. The ESPB is performed under US guidance, and the target is the transverse process, which is easily identifiable and is relatively distant from neural or major vascular structures [14]. ESPB can also be a valid alternative if there are contraindications to paravertebral block, such as coagulopathy or anticoagulant therapy. ESPB is safer because the target is the transverse process, avoiding accidental pleural punctures; moreover, an advantage is that it provides extensive analgesia with a single puncture [7]. Dexmedetomidine is a potent $\alpha 2$ agonist and is now emerging as an adjuvant to regional anesthesia and analgesia. It can prolong the duration of the nerve block anesthesia when used with LA, and has only a few side effects, resulting in increased effectiveness of the block in terms of duration, less use of opioids and shorter hospital stays, in the absence of clinically significant side effects (bradycardia, hypotension, nausea, vomiting, pruritus) $[4,15,16]$. In some literature studies, the efficacy of dexmedetomidine is comparable to that of dexamethasone, already widely used as an adjuvant in locoregional anesthesia [4].

Some studies indicate that dexmedetomidine, a selective $\alpha 2$-adrenoceptor agonist, may be useful to prevent withdrawal syndrome $[17,18]$. In our experience, although limited, there were no episodes of nausea, vomiting, postoperative shiver, pruritus, sedation, bradycardia, hypotension, desaturation or constipation.

\section{Conclusion}

Given our observations, we believe that this approach could be an anesthetic alternative that could be practiced in all patients who take advantage of opioid-free anesthesia either for respiratory problems or for other problems such as chronic use of opioid drugs. Furthermore, this technique can be generalized for all thoracic abdominal surgery. Shorter hospital stays and rapid recanalization could make these interventions suitable for day surgery.

\section{Abbreviations \\ COPD: Chronic obstructive pulmonary disease; ESPB: Erector spinae plane block; LA: Local anesthetic; MAC: Minimum alveolar concentration; OSAS: \\ Obstructive sleep apnea syndrome; PAI-1: Plasminogen activator inhibitor-1; PONV: Postoperative nausea and vomiting; TOF: Train of four; US: Ultrasound; VAS: Visual analog scale.}

\section{Acknowledgements}

This research did not receive any specific grant from funding agencies in the public, commercial, or not-for-profit sectors.

\section{Authors' contributions}

Conception: AC, DE, RG; Design of the work: AM, AC, GS; Acquisition: AC, AM; Analysis: AC, DE, RG; Interpretation of data: AM, GS; Drafted the work: AC, DE, RG; Revised the work: GS, AC; The manuscript has been read and approved by all the authors, the requirements for authorship have been met, and author believes that the manuscript represents honest work. All authors read and approved the final manuscript.

\section{Funding}

This research did not receive any specific Grant from funding agencies in the public, commercial, or not-for-profit sectors.

\section{Availability of data and materials}

All data generated or analyzed during this study are included in this published article.

\section{Declarations}

Ethics approval and consent for participate Not applicable. 


\section{Consent for publication}

Written informed consent was obtained from the patient for publication of this case report and any accompanying images. A copy of the written consent is available for review by the Editor-in-Chief of this journal.

\section{Competing interests}

The authors declare that they have no competing interests.

Received: 3 November 2020 Accepted: 15 April 2021

Published online: 29 May 2021

\section{References}

1. Forero M, Adhikary SD, Lopez H, Tsui C, Chin KJ. The erector spinae plane block: a novel analgesic technique in thoracic neuropathic pain. Reg Anesth Pain Med. 2016;41(5):621-7. https://doi.org/10.1097/AAP.00000 00000000451.

2. Mulier J. Perioperative opioids aggravate obstructive breathing in sleep apnea syndrome: mechanisms and alternative anesthesia strategies. Curr Opin Anesthesiol. 2016;29:129-33. https://doi.org/10.1097/ACO.00000 00000000281.

3. Chin KJ, Malhas L, Perlas A. The erector spinae plane block provides visceral abdominal analgesia in bariatric surgery: a report of 3 cases. Reg Anesth Pain Med. 2017;42(3):372-6. https://doi.org/10.1097/AAP.00000 00000000581 .

4. Gao Z, Xiao Y, Wang Q, Li Y. Comparison of dexmedetomidine and dexamethasone as adjuvant for ropivacaine in ultrasound-guided erector spinae plane block for video-assisted thoracoscopic lobectomy surgery: a randomized, double-blind, placebo-controlled trial. Ann Transl Med. 2019;7(22):668. https://doi.org/10.21037/atm.2019.10.74

5. Rawal N. Epidural technique for postoperative pain: gold standard no more? Reg Anesth Pain Med. 2012;37(3):310-7. https://doi.org/10.1097/ AAP.0b013e31825735c6

6. Tulgar S, Selvi O, Kapakli MS. Erector spinae plane block for different laparoscopic abdominal surgery: case series. Case Rep Anesthesiol. 2018;18(2018):3947281. https://doi.org/10.1155/2018/3947281.

7. Fusco P, Di Carlo S, Scimia P, Luciani A, Petrucci E, Mariangeli F. Could the new ultrasound-guided erector spinae plane block be a valid alternative to paravertebral block in chronic chest pain syndromes? Minerva Anestesiol. 2017;83(10):1112-3.

8. Beloeil H. Opioid-free anesthesia. Best Pract Res Clin Anaesthesiol. 2019;33(3):353-60. https://doi.org/10.1016/j.bpa.2019.09.002.
9. Schwartzmann A, Peng P, Maciel MA, Forero M. Mechanism of the erector spinae plane block: insights from a magnetic resonance imaging study. Can J Anaesth. 2018;65(10):1165-6. https://doi.org/10.1007/ s12630-018-1187-y.

10. Vidal E, Giménez H, Forero M, Fajardo M. Erector spinae plane block: a cadaver study to determine its mechanism of action. Rev Esp Anestesio Reanim. 2018;65(9):514-9. https://doi.org/10.1016/j.redare.2018.09.002.

11. Coviello A, Vargas M, Castellano G, Maresca A, Servillo G. Ultrasound guided erector spinae plane block (US-ESPB) — anesthetic block: case report. Clin Case Rep. 2020. https://doi.org/10.1002/ccr3.3253.

12. Milone M, Di Minno MN, Musella M, Maietta P, lacovazzo C, Milone F. Ultrasound-guided transversus abdominis plane block for retroperitoneal varicocele repair. Could it be an anesthesia method? Updates Surg. 2013;65:225-30.

13. Selvi O, Tulgar S. Ultrasound guided erector spinae plane block as a cause of unintended motor block. Rev Esp Anestesiol Reanim. 2018;65(10):58992. https://doi.org/10.1016/j.redare.2018.05.003.

14. Luis-Navarro JC, Seda-Guzmán M, Luis-Moreno C, Chin KJ. Erector spinae plane block in abdominal surgery: case series. Indian J Anaesth. 2018;62(7):549-54. https://doi.org/10.4103/ija.IJA_57_18.

15. Andersen $\mathrm{JH}, \mathrm{Grevstad} \mathrm{U}$, Siegel $\mathrm{H}$, et al. Does dexmedetomidine have a perineural mechanism of action when used as an adjuvant to ropivacaine?: A paired, blinded randomized trial in healthy volunteers. Anesthesiology. 2017;126:66-73. https://doi.org/10.1097/ALN.0000000000 001429.

16. Rancourt MP, Albert NT, Côté M, et al. Posterior tibial nerve sensory blockade duration prolonged by adding dexmedetomidine to ropivacaine. Anesth Analg. 2012;115:958-62. https://doi.org/10.1213/ANE.0b013 e318265bab7.

17. Mondardini MC, Sperotto F, Daverio M, et al. Efficacy and safety of dexmedetomidine for prevention of withdrawal syndrome in the pediatric intensive care unit: protocol for an adaptive, multicenter, randomized, double-blind, placebo-controlled, non-profit clinical trial. Trials. 2019;20:710. https://doi.org/10.1186/s13063-019-3793-6.

18. Honey BL, Benefield RJ, Miller JL, Johnson PN. a2-Receptor agonists for treatment and prevention of iatrogenic opioid abstinence syndrome in critically III patients. Ann Pharmacother. 2009;43(9):1506-11. https://doi. org/10.1345/aph.1M161.

\section{Publisher's Note}

Springer Nature remains neutral with regard to jurisdictional claims in published maps and institutional affiliations.
Ready to submit your research? Choose BMC and benefit from:

- fast, convenient online submission

- thorough peer review by experienced researchers in your field

- rapid publication on acceptance

- support for research data, including large and complex data types

- gold Open Access which fosters wider collaboration and increased citations

- maximum visibility for your research: over 100M website views per year

At BMC, research is always in progress.

Learn more biomedcentral.com/submissions 